\title{
Deformation-induced endothelin B receptor-mediated smooth muscle cell apoptosis is matrix-dependent
}

\author{
M Cattaruzza ${ }^{1}$, MM Berger ${ }^{1}$, M Ochs $^{3}$, A Fayyazi $^{2}$, L Füzesi ${ }^{2}$, \\ J Richter ${ }^{3}$ and M Hecker*,1 \\ 1 Department of Cardiovascular Physiology, University of Goettingen, \\ Humboldtallee 23, 37073 Goettingen, Germany \\ 2 Department of Pathology, University of Goettingen, Robert-Koch-Str. 40, \\ 37075 Goettingen, Germany \\ ${ }^{3}$ Department of Electron Microscopy, University of Goettingen, Kreuzbergring \\ 36, 37075 Goettingen, Germany \\ * Corresponding author: M Hecker, Department of Cardiovascular Physiology, \\ Humboldtallee 23, 37073 Goettingen, Germany. Fax: +49-551-395895 \\ E-mail: hecker@veg-physiol.med.uni-goettingen.de
}

Received 9.5.01; revised 17.7.01; accepted 24.7.01

Edited by RA Knight

\section{Abstract}

To maintain normal blood flow, pressure overload in both arteries and veins requires a structural adaptation of the vessel wall (remodelling) that involves smooth muscle cell (SMC) hypertrophy and/or hyperplasia. Due to its potent vasoconstrictor and growth-promoting effects, endothelin-1 (ET-1) is a likely candidate to initiate and/or promote remodelling in blood vessels exposed to a chronic increase in blood pressure. To test this hypothesis, isolated segments of the rabbit carotid artery and jugular vein were perfused at different levels of intraluminal pressure. In both types of segments, pressure overload (160 and $20 \mathrm{mmHg}$, respectively) resulted in an increase in endothelial prepro-ET-1 and SMC endothelin B receptor $\left(E T_{B}-R\right)$ expression. Moreover, in pressurised segments from the carotid artery an $E T_{B}-R$ antagonistsensitive increase in SMC apoptosis in the media was observed, while in the vein medial SMC started to proliferate. Isolated SMC from these rabbit blood vessels as well as from the aorta and vena cava of the rat, when cultured on a collagen or laminin matrix, uniformly revealed an $\mathrm{ET}_{\mathrm{B}}-\mathrm{R}$-mediated increase in apoptosis upon exposure to mechanical deformation plus exogenous ET-1 (10 nmol/L). However, when grown on a fibronectin matrix, the cultured SMC did not respond with an increase in apoptosis under otherwise identical experimental conditions. These findings suggest that deformationinduced activation of the endothelin system in the vessel wall not only plays a crucial role in remodelling, but that the structural components of the vessel wall, in particular the cellmatrix interaction, determine how SMC respond phenotypically to these changes in gene expression.

Cell Death and Differentiation(2002) 9,219-226. DOI: 10.1038/sj/ cdd/4400936

Keywords: blood pressure; endothelin-1; vascular remodelling; fibronectin; cell cycle
Abbreviations: $E C E-1$, endothelin converting enzyme 1; $E T_{A}-R$, endothelin type $A$ receptor; $E T_{B}-R$, endothelin type $B$ receptor; (pp)ET-1, (prepro)-endothelin 1; RT-PCR, reverse transcriptionpolymerase chain reaction; SMC, smooth muscle cell(s); TEM, transmission electron microscopy

\section{Introduction}

Nutritive blood flow to organs and tissues is regulated locally by adjusting the resistance of the vascular bed to the demand (for review see $\left.{ }^{1}\right)$. Chronic pressure overload as a consequence of, e.g. arterial hypertension or following venous bypass grafting, requires an adaptive response of the vascular bed to maintain adequate organ perfusion. Presumably, the ability of the vessel wall to compensate the distending pressure through vasoconstriction defines the threshold beyond which the architecture of the vessel wall, especially the number and/or morphology of SMC needs to be altered. Whereas certain events in this adaptive process, such as an initial phase of smooth muscle cell apoptosis in response to an enhanced pressure load as well as their chronological sequence start to be unravelled, ${ }^{2}$ molecular mechanisms involved in the remodelling of the vessel wall are poorly characterised. Understanding the sequence of events leading to hyperplasia or hypertrophy of the vessel wall at this level, however, may yield important clues to the therapy of vascular complications such as hypertensioninduced arterial remodelling, restenosis following angioplasty or the vasculopathy of venous bypass grafts.

Due to its potent vasoconstrictor ${ }^{3}$ and growth-promoting ${ }^{4}$ effects, the vascular endothelin system, i.e. the secreted peptide endothelin-1 (ET-1) and its two receptors $A$ and $B$ $\left(E T_{A}-R\right.$ and $\left.E T_{B}-R\right)$, may function as a molecular switch between vasoconstriction and remodelling in the short or long-term adaptation of blood vessels to a chronic increase in blood pressure. Indeed, ET-1 synthesis has been reported to be increased in several cardiovascular diseases associated with smooth muscle cell hyperplasia or hypertrophy. ${ }^{5,6}$ In animal models of arterial hypertension, ET-1 has also been implicated in vascular remodelling (for review see ${ }^{7}$ ). Moreover, deformation of endothelial cells seems to be a powerful stimulus for up-regulating ET-1 synthesis in the vessel wall. ${ }^{8}$

To test whether the peptide is involved in the early phases of pressure-induced vascular remodelling, we have set up an in situ model in which isolated segments of the carotid artery and jugular vein of the rabbit are perfused at different levels of intraluminal pressure.

\section{Results}

\section{Pressure-dependent activation of the} endothelin system

To confirm our previous findings of pressure-dependent activation of the endothelin system in the vessel wall (cf. 
references ${ }^{8,9}$ ) a new series of experiments was performed both with isolated perfused segments of the carotid artery and jugular vein of the rabbit (Figure 1). In both types of blood vessels prepro-ET-1 expression and that of the $E_{B}-R$ were up-regulated in response to perfusion at a supra-physiological pressure of 160 and $20 \mathrm{~mm} \mathrm{Hg}$, respectively, for $6 \mathrm{~h}$. $E T_{A^{-}}-\mathrm{R}$ expression and that of endothelin-converting enzyme 1 (ECE1 ), on the other hand, appeared to be pressure-insensitive.

\section{Functional significance of ET-1 and $\mathrm{ET}_{\mathrm{B}}-\mathrm{R}$ expression in the pressurised carotid artery}

While there was a significant increase in $E T_{B}$-R-mediated vasoconstriction in the pressurised jugular vein, no such effect was observed in the carotid artery, which constricted only in response to $\mathrm{ET}_{\mathrm{A}}-\mathrm{R}$ stimulation (not shown). However, one functional consequence of the pressure-induced increase in ppET-1 and $\mathrm{ET}_{\mathrm{B}}-\mathrm{R}$ expression in the rabbit carotid artery was an increase in apoptosis that was sensitive to the $E T_{B}-R$ specific antagonist BQ788 $(1 \mu \mathrm{mol} / \mathrm{L})$ but not to the $\mathrm{ET}_{\mathrm{A}}-\mathrm{R}-$

A

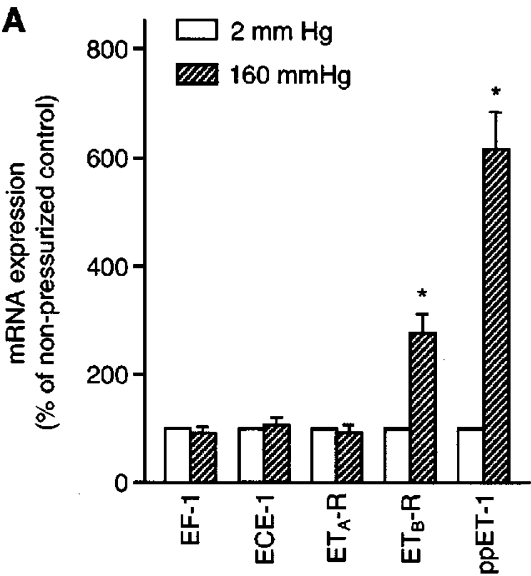

RbCA

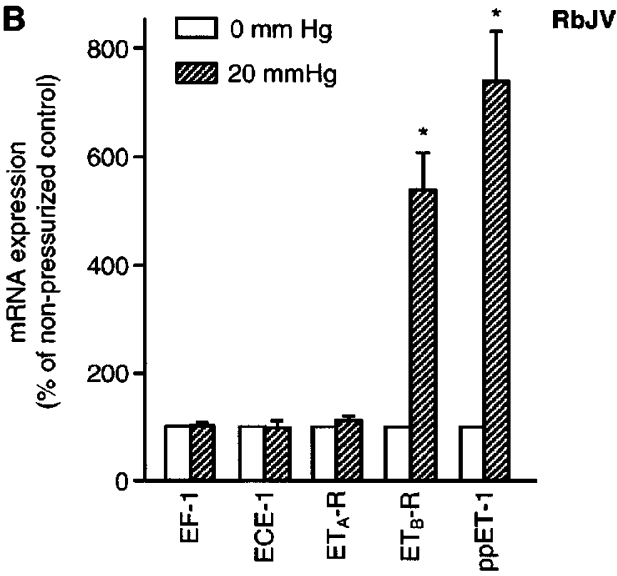

Figure 1 Pressure-induced changes in expression of the endothelin system in isolated perfused segments of $(\mathbf{A})$ the rabbit carotid artery $(\mathrm{RbCA})$ and $(\mathbf{B})$ the jugular vein (RbJV), as determined by RT - PCR analysis. Segments were perfused for $6 \mathrm{~h}$ at $37^{\circ} \mathrm{C}$ at the indicated perfusion pressure $\left(n=3,{ }^{\star} P<0.05\right.$ versus non-pressurised control, i.e. $100 \%$ ) specific antagonist BQ123 ( $1 \mu \mathrm{mol} / \mathrm{L})$, as judged by monitoring the activity of the apoptosis-specific protease caspase-3 (Figure 2). In contrast, control experiments with segments of the carotid artery perfused at low-pressure $(2 \mathrm{~mm} \mathrm{Hg}$ ) plus exposure to BQ123 or BQ788 did not affect caspase-3 activity (not shown).

Pressure-induced SMC apoptosis was clearly dependent on endothelial ET-1 synthesis for endothelium-denuded

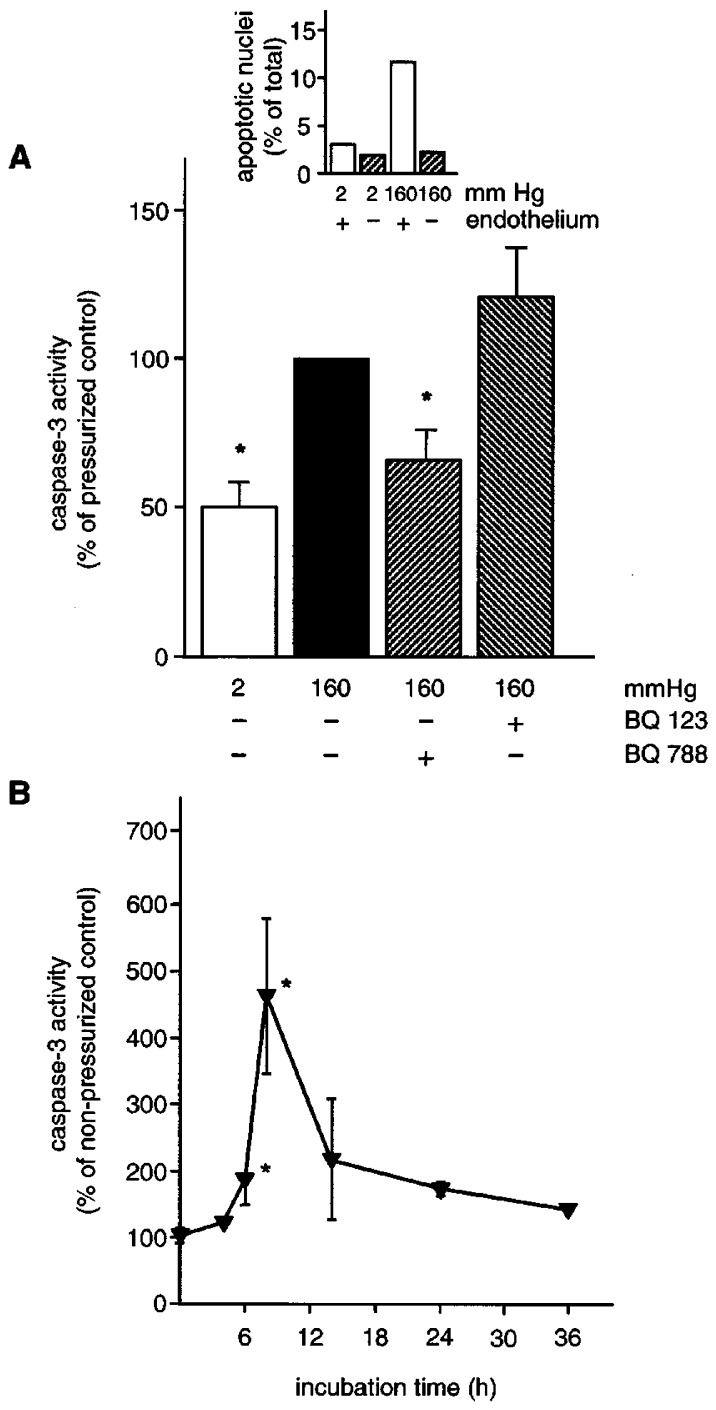

Figure $2 \mathrm{ET}_{\mathrm{B}}$-R-mediated induction of apoptosis in pressurised segments of the rabbit carotid artery. The isolated segments were perfused for $6 \mathrm{~h}$ at 2 or $160 \mathrm{~mm} \mathrm{Hg}$, respectively, followed by (A) $18 \mathrm{~h}$ or (B) $0-36 \mathrm{~h}$ incubation under static conditions. BQ788 and BQ123 ( $1 \mu \mathrm{mol} / \mathrm{L}$ each) were administered $20 \mathrm{~min}$ before termination of perfusion and throughout the incubation period $(n=7-$ 10). Caspase-3 activity is expressed relative (\%) to that in pressurised (A) or non-pressurised (B) control segments $\left({ }^{*} P<0.05\right.$ versus pressurised or nonpressurised controls, respectively, i.e. 100\%). The inset depicts an exemplary experiment of endothelium-intact and denuded segments of the rabbit carotid artery treated as described before. The number of apoptotic nuclei in the media was analyzed in cross sections stained with the fluorescent DNAbinding dye Hoe 33342 (see Materials and Methods section). Relative amounts (\%) of apoptotic nuclei were determined by counting numbers of total and apoptotic nuclei. An average of $854 \pm 32$ nuclei per cross section was counted in these experiments $(n=7-10)$ 
segments, despite the increase in $\mathrm{ET}_{\mathrm{B}}-\mathrm{R}$ expression, did not reveal any increase in caspase- 3 activity above the level of endothelium-intact control segments (Figure 2A, inset). Moreover, the increase in caspase-3 activity was time-dependent with a maximum at $14 \mathrm{~h}$, i.e. pressurising of the segments for $6 \mathrm{~h}$ followed by static incubation for another $8 \mathrm{~h}$ (Figure 2B), and associated with an increase in chromatin condensation of the medial SMC (not shown).

\section{Identity and localisation of apoptotic cells in the pressurised carotid artery}

To verify the identity of the dying cells, cross sections of the perfused carotid arteries were analyzed by transmission electron microscopy (TEM). TEM revealed that apoptotic cell death affected SMC predominantly at the media-adventitia border and, in addition, was accompanied by matrix degradation, leading to a dissolution of the tightly packed smooth muscle cell-containing septae which are typical for this type of blood vessel (Figure 3).

Interestingly, no change in SMC apoptosis was detected in pressurised segments of the jugular vein, irrespective of whether this was analyzed by chromatin condensation or TEM (not shown). In contrast, the venous segments revealed an increased number of PCNA-positive (i.e. proliferating) SMC in the media as a result of the elevated perfusion pressure. This effect was induced by endogenous ET-1 and mediated through activation of the $E T_{B}-R$, as demonstrated by the inhibitory effect of BQ788 but not BQ123 (Figure 4 ).

This $E T-1 / E T_{B}-R$-mediated growth response was only observed in the jugular vein. In pressurised segments of the carotid artery, the number of proliferating SMC did not differ from those in non-pressurised control segments, as analyzed by both PCNA and Ki67 immunohistochemistry (not shown).

\section{Smooth muscle cell type versus structural differences}

To address the question whether the differential phenotypic response of the native venous and arterial SMC to activation of the endothelin system was due to the in situ environment of the cells or due to a vessel type-specific in situ differentiation, SMC were isolated both from the jugular vein and carotid

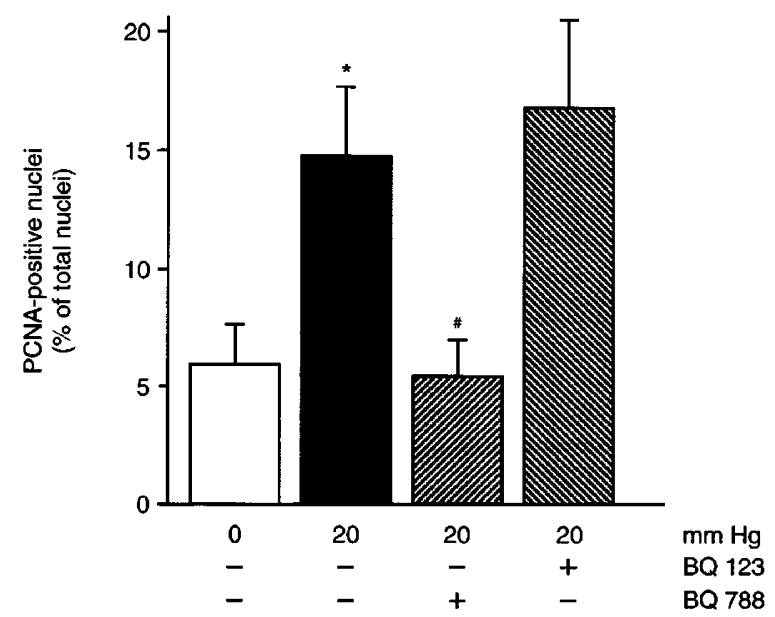

Figure $4 \mathrm{ET}_{\mathrm{B}}$-R-mediated proliferation of $\mathrm{SMC}$ in segments of the rabbit jugular vein. The segments were perfused for $6 \mathrm{~h}$ at 0 or $20 \mathrm{~mm} \mathrm{Hg}$, followed by a $36 \mathrm{~h}$ incubation period under static conditions. BQ788 and BQ123 $(1 \mu \mathrm{mol} / \mathrm{L}$ each) were administered $20 \mathrm{~min}$ before termination of perfusion and throughout the incubation period $(n=6-7)$. Immunohistochemistry for the cell cycle-specific antigen PCNA was performed as described in the Materials and Methods section. The number of PCNA-positive nuclei is expressed relative $(\%)$ to the total number of nuclei present in the cross section analyzed. Only nuclei from the intima and media were counted $\left({ }^{*} P<0.05\right.$ versus nonpressurised controls, $\# P<0.05$ versus pressurised controls)
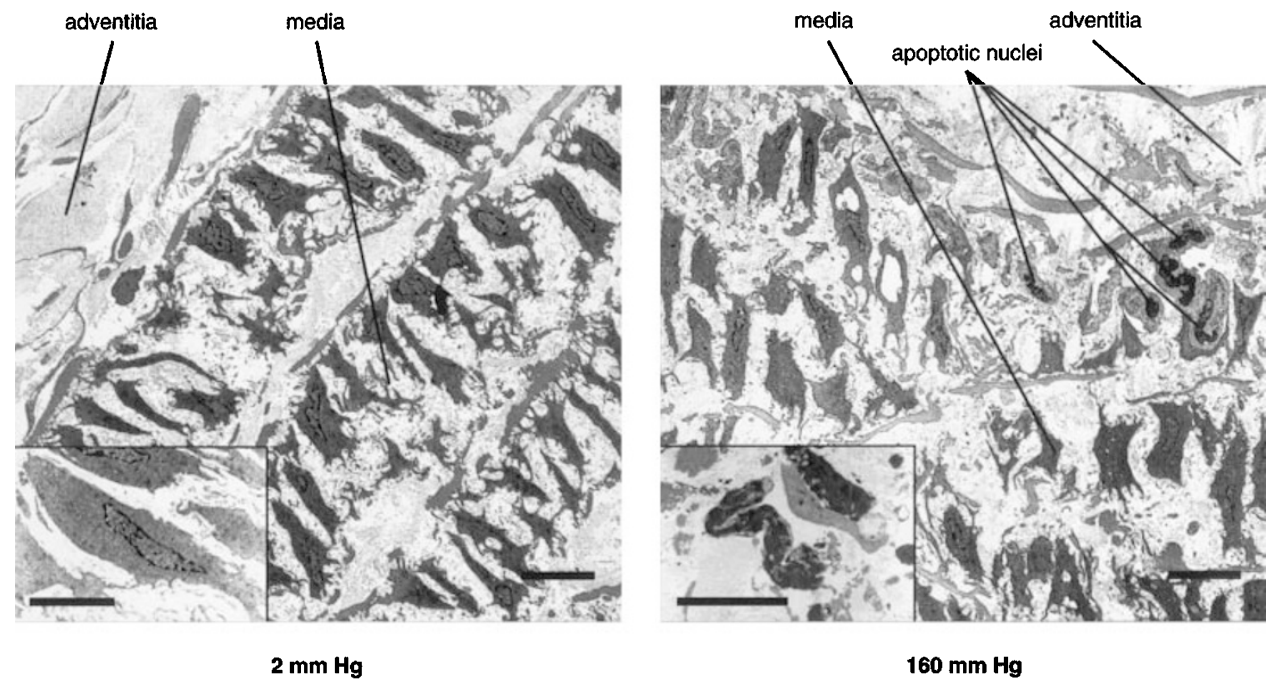

Figure 3 Representative TEM micrographs of cross sections of the rabbit carotid artery perfused at $2 \mathrm{or} 160 \mathrm{~mm} \mathrm{Hg}$ for $6 \mathrm{~h}$ followed by $18 \mathrm{~h}$ incubation in medium The media-adventitia border is shown at low magnification. While SMC from segments perfused at $2 \mathrm{~mm} \mathrm{Hg}$ show no signs of cell death (A), apoptotic SMC can be found after perfusion of the segments at $160 \mathrm{~mm} \mathrm{Hg}(\mathbf{B})$. The insets show a single normal or apoptotic SMC. Scale bars indicate distances of $5 \mu \mathrm{m}$ (insets) and $10 \mu \mathrm{m}$ (overviews), respectively 
artery and grown on collagen-coated culture dishes or on BioFlex collagen type I elastomers, respectively. To mimic the pressure-dependent deformation of the SMC in the vessel wall, cyclic stretch ( $15 \%$ for $6 \mathrm{~h}$ at $0.5 \mathrm{~Hz}$ ) was applied to the cells on the elastomers. This level of stretch is within the physiological range and maximum effects were obtained without visible damage to the cells. ${ }^{10}$ Interestingly, SMC isolated from both rabbit blood vessels showed a response similar to that of the carotid artery in situ. In the presence of exogenous ET-1 $(10 \mathrm{nmol} / \mathrm{L}$, i.e. to mimic the pressureinduced increase in endothelial ppET-1 expression), a
BQ788-sensitive but BQ123-insensitive increase in apoptosis was observed (Figure 5). The basal rate of proliferation of the cultured SMC, on the other hand, did not change under these conditions, as monitored by Ki67 immunohistochemistry (cf. Figure 7).

To verify that the rabbit cultured SMC also react with a marked increase in $\mathrm{ET}_{\mathrm{B}}-\mathrm{R}$ gene expression upon exposure to cyclic stretch, RT-PCR analyses were performed revealing virtually the same results (Figure $5 \mathrm{~A}$ and $\mathrm{B}$, insets) as shown for the native cells (cf. Figure 1).
A

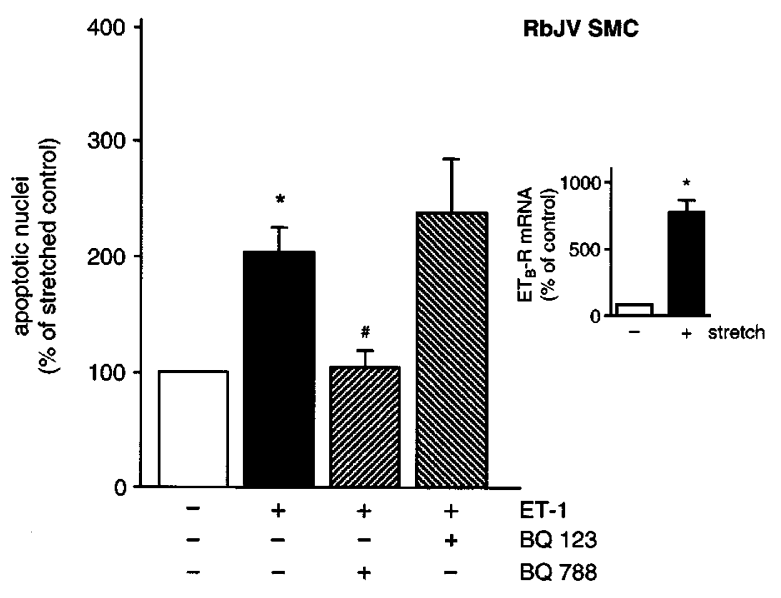

B

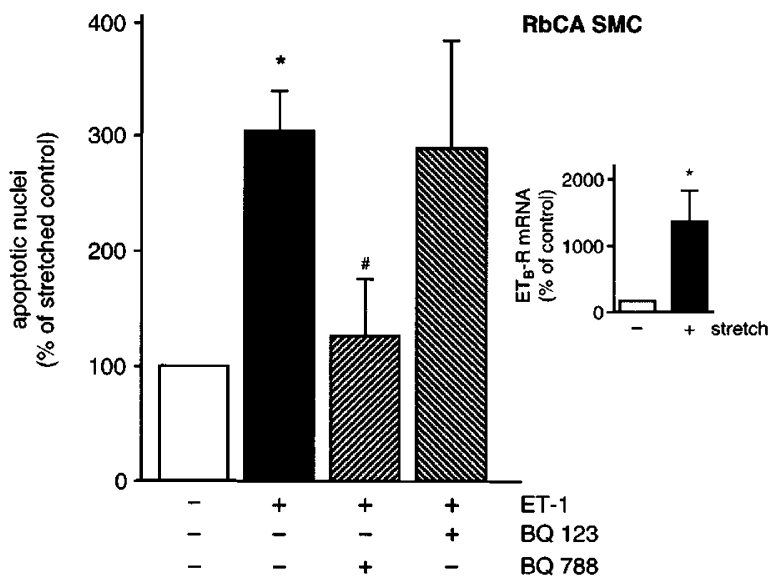

Figure 5 Chromatin condensation in cultured SMC derived from the rabbit carotid artery (RbCA SMC, A) and jugular vein (RbJV SMC, B) exposed to cyclic stretch. Cells were incubated with or without ET-1 $(0.01 \mu \mathrm{mol} / \mathrm{L})$ in the absence or presence of BQ788 or BQ123 $(1 \mu \mathrm{mol} / \mathrm{L}$ each $)$ and stretched for $6 \mathrm{~h}$ at $0.5 \mathrm{~Hz}$ and $15 \%$ elongation. After an additional incubation for $18 \mathrm{~h}$ under static conditions, cells were fixed and nuclei stained with Hoe 33342 followed by evaluation of apoptotic chromatin condensation. Summarised are the data from four independent experiments with different batches of cells with the number of apoptotic nuclei expressed relative (\%) to that in stretched cells not exposed to ET-1 (designated control, range of apoptotic nuclei $3-8 \%$ ). ${ }^{*} P<0.05$ versus stretched control, i.e. $100 \%,{ }^{\#} P<0.05$ versus $\mathrm{ET}-1$. The insets depict the stretch-induced increase in $E T_{B}-R$ mRNA abundance in these cells, as judged by RT-PCR analysis, of four samples from the same batches of SMC and stretched in parallel with the SMC used for analysis of chromatin condensation ( ${ }^{\star} P<0.05$ versus non-stretched SMC, i.e. $\left.100 \%\right)$
A

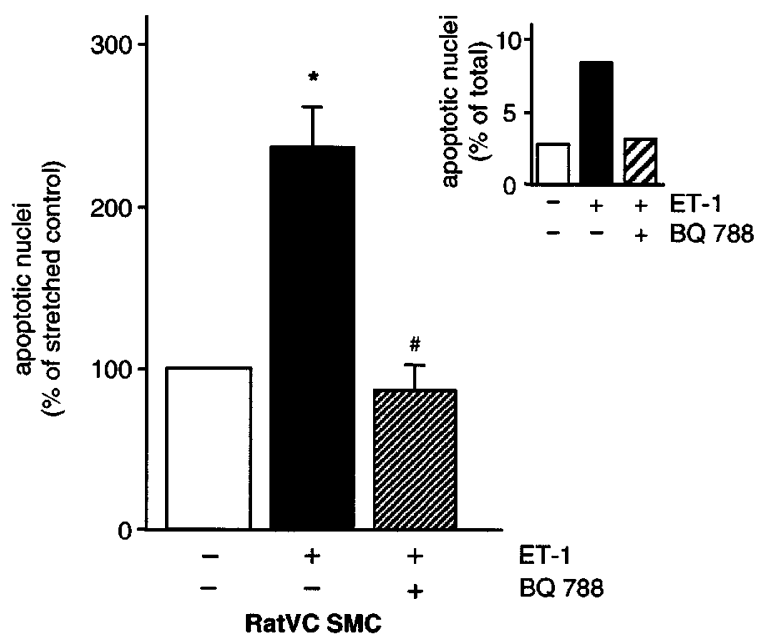

B

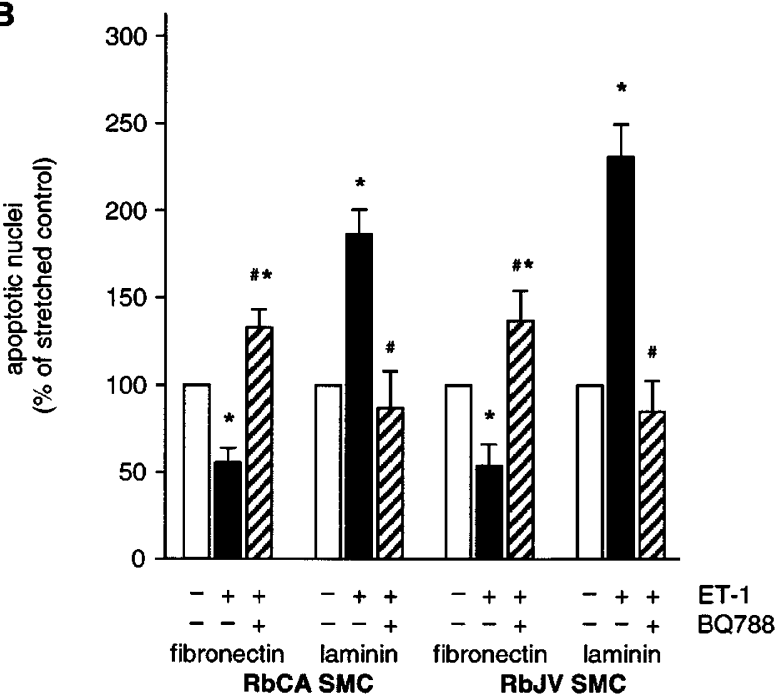

Figure 6 (A) Chromatin condensation in cultured SMC derived from the rat vena cava (RatVC). Cells were treated as described in the legend to Figure 5. Summarised are the data from eight independent experiments with different batches of cells $\left({ }^{*} P<0.05\right.$ versus control, i.e. $100 \%$; ${ }^{\#} P<0.05$ versus ET- 1 ). The inset depicts an exemplary experiment with rat aortic cultured SMC. (B) Chromatin condensation in cultured SMC derived from the rabbit carotid artery (RbCA SMC) and jugular vein (RbJV SMC), respectively. Cells were grown on laminin or fibronectin elastomers and treated in the same way as described in the legend to Figure 5. The data presented summarise four (laminin) or seven (fibronectin) independent experiments with cells derived from different animals $\left({ }^{*} P<0.05\right.$ versus stretched control, i.e. $100 \% ;{ }^{\#} P<0.05$ versus ET- 1$)$ 
A

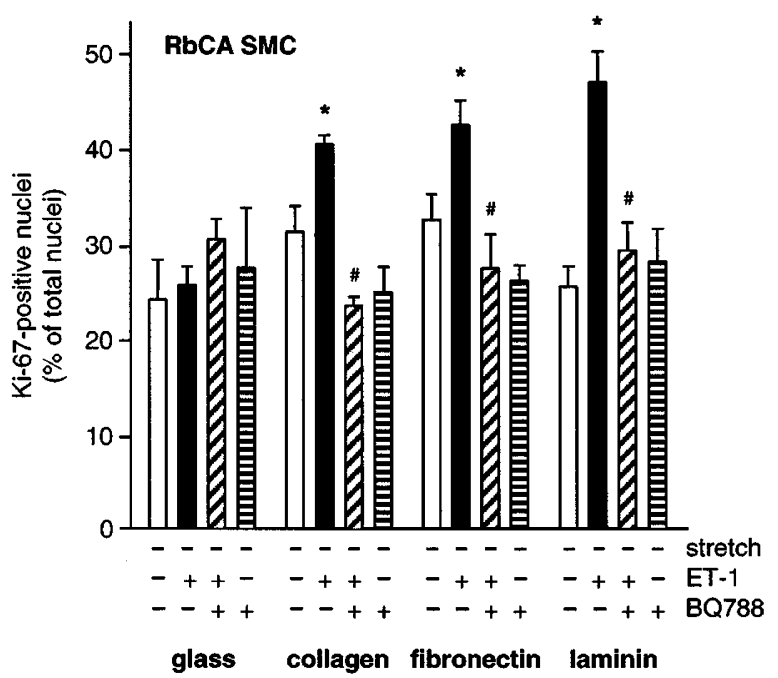

B

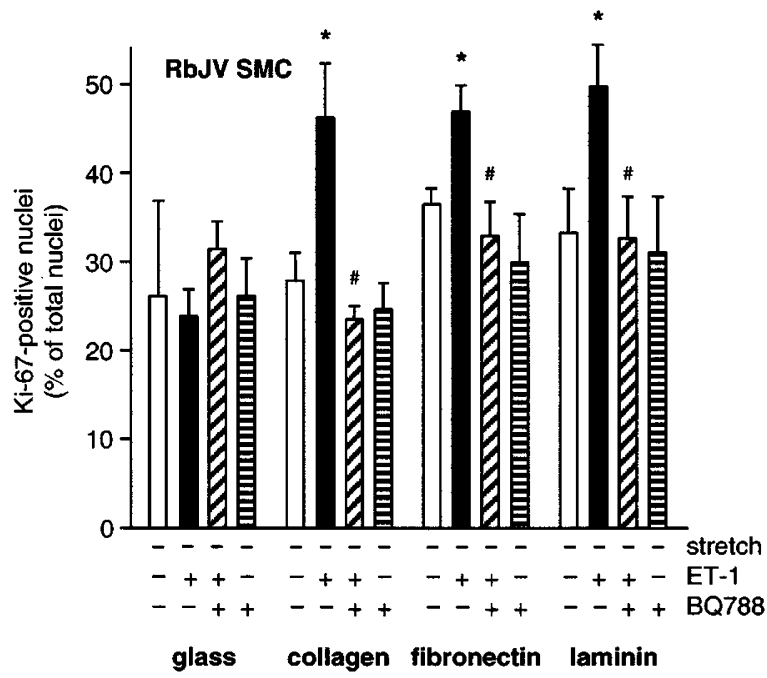

Figure 7 ET-1-dependent SMC proliferation as assessed by immunofluorescence analysis (Ki67-positive nuclei) of SMC derived from (A) the rabbit carotid artery (RbCA SMC) and (B) the rabbit jugular vein (RbJV SMC) grown on collagen-coated glass cover slides (glass) or collagen, laminin or fibronectin elastomers. SMC were treated as described in the legend to Figure 5. The data of four independent experiments are summarised $\left({ }^{*} P<0.05\right.$ versus stretched control, ${ }^{\#} P<0.05$ versus stretch and ET-1)

To rule out a species-specific behaviour of the venous and arterial rabbit SMC, comparative experiments were performed with SMC isolated from the aorta and vena cava of the rat. We have previously reported that in rat aortic cultured SMC exposure to cyclic stretch in the presence of exogenous ET-1 leads to an increase in apoptosis. ${ }^{10} \mathrm{~A}$ parallel exemplary experiment with these cells indeed revealed a threefold increase in apoptosis in cells exposed to ET-1 as compared to cells stretched in the absence of ET-1, and this effect was completely suppressed by BQ788 $(1 \mu \mathrm{mol} / \mathrm{L}$; Figure $6 \mathrm{~A}$ inset) but not BQ123 (not shown). Moreover, SMC derived from the rat vena cava responded in a manner identical to their arterial counterparts (Figure $6 A)$.
In contrast to SMC isolated from the rabbit carotid artery or jugular vein and cultured on collagen type I or laminin elastomers, SMC grown on fibronectin elastomers and subjected to the same stretch protocol showed a significant decrease in apoptosis when exposed to exogenous ET-1. Interestingly, this effect was also reversed by BQ788 (Figure 6B) while BQ123 had no effects (not shown). Moreover, counting the number of Ki67-positive nuclei, i.e. counting proliferating cells, revealed a simultaneous BQ788-sensitive but BQ123-insensitive (not shown) growth-promoting effect of ET-1 in stretched rabbit SMC, but no differences with respect to the origin (carotid artery or jugular vein) or the composition of the matrix (collagen, laminin or fibronectin) they were grown on (Figure 7).

\section{Discussion}

\section{Deformation-induced expression of the endothelin system}

Remodelling of the vessel wall in response to pressure overload in conduit arteries is characterised by media hypertrophy and increased matrix protein synthesis, while in resistance-sized arteries or veins SMC hyperplasia is frequently observed. ${ }^{11,12}$ Several lines of evidence suggest that ET-1 may play a pivotal role in these adaptive responses. ET-1 is not only a powerful co-mitogen, ${ }^{13}$ its synthesis by the endothelium also is strongly up-regulated by (blood) pressureinduced distension of the vessel wall. ${ }^{9}$ In addition, $\mathrm{ET}_{\mathrm{B}}-\mathrm{R}$ mRNA abundance in the SMC is markedly increased under these conditions.

At present, detection of $E T_{B}-R$ protein in rabbit $S M C$ is not possible due to the lack of a suitable antibody. ${ }^{9}$ In contrast, Western blot detection of $\mathrm{ET}_{\mathrm{B}}-\mathrm{R}$ protein does not pose a problem for rat cultured $\mathrm{SMC}^{14}$ where the stretchinduced increase in $\mathrm{ET}_{\mathrm{B}}-\mathrm{R}$ protein can readily be demonstrated (not shown). This is why verification of changes in $\mathrm{ET}_{\mathrm{B}}-\mathrm{R}$ protein expression in rabbit $\mathrm{SMC}$ had to be done by monitoring BQ788-sensitive, hence $\mathrm{ET}_{\mathrm{B}}$-R-mediated functional responses to ET-1.

\section{Arterial smooth muscle cell apoptosis}

Irrespective of the marked pressure-induced increase in $\mathrm{ET}_{\mathrm{B}^{-}}$ $R$ expression, segments of the carotid artery, in contrast to segments of the jugular vein, constricted only in response to $E T_{A}-R$ stimulation, indicating that pressure-induced $E T_{B}-R$ expression in these blood vessels does not contribute to the maintenance of SMC tone. ${ }^{9}$ Moreover, despite the increase in endothelial ET-1 synthesis there was no appreciable change in SMC proliferation in these segments. In contrast, an $\mathrm{ET}_{\mathrm{B}}-\mathrm{R}-$ mediated rise in the number of apoptotic SMC in the media of the pressurised carotid artery was noted. This increased apoptosis was observed in endothelium-intact segments only, supporting the hypothesis that in the vessel wall the endothelium represents the predominant if not sole source of ET-1 in conditions of an enhanced pressure load. ${ }^{8,9}$

Another interesting aspect of this pressure-induced $\mathrm{ET}_{\mathrm{B}^{-}}$ R-mediated apoptosis in the artery was that it appeared to be most prominent at the interface between media and 
adventitia, i.e. where the pressure-induced increase in wall tension causing longitudinal stretching of the SMC is highest. ${ }^{1,15}$ In addition, TEM analysis suggested that SMC apoptosis is accompanied by reorganisation of the extracellular matrix, a process potentially marking the onset of remodelling in the vessel wall.

However, ET-1 not only promotes caspase-3-mediated apoptosis in SMC as shown herein, but, under different experimental conditions, may exert the opposite effect. ${ }^{16}$ This apparent discrepancy is best explained by the differences in SMC endothelin receptor distribution between the two studies, resulting in different functional responses to ET-1. Whereas Diep et al. ${ }^{16}$ used quiescent mesenteric SMC that almost exclusively express the $E T_{A}-R$, we employed both native and cultured $S M C$ in which $E T_{B}-R$ expression was markedly enhanced in response to mechanical deformation.

\section{Conversely: SMC proliferation in the vein}

Unlike their arterial counterparts, no appreciable increase in SMC apoptosis was detected in pressurised segments of the rabbit jugular vein. However, in keeping with the pressureinduced $\mathrm{ET}_{\mathrm{B}}-\mathrm{R}$-mediated vasoconstriction, ${ }^{9}$ a pressureinduced rise in the number of PCNA-positive nuclei was detected in the media, indicative of a proliferation of the venous SMC that was BQ788 but not BQ123 sensitive. Taken together, the aforementioned findings demonstrate that native SMC of the same species but localised to arteries or veins respond differently to $E T_{B}-R$ stimulation by either undergoing programmed cell death or entering the cell cycle.

\section{Arteriovenous SMC differentiation versus cell-matrix interaction}

One hallmark of vascular SMC is their plasticity, i.e. their capacity to quickly adapt to a different environment. ${ }^{17}$ Therefore, we asked the question whether SMC isolated from the carotid artery or jugular vein of the rabbit and cultured under the same experimental conditions maintain this divergent response to $E T_{B}-R$ stimulation. The answer is that the venous SMC, irrespective of the species (rabbit or rat), loose this characteristic upon culturing and like their arterial counterparts reveal an enhanced ET-1-induced $E T_{B}-R$ mediated apoptosis in response to cyclic stretch. It would appear, therefore, that it is the structure and/or composition of the extracellular matrix, which determines how SMC in arteries or veins react phenotypically to an overt pressure load. To assess the potential role of extracellular matrix proteins in this process, we cultured SMC derived from the rabbit carotid artery and jugular vein in addition to collagen also on laminin or fibronectin elastomers. In contrast to cells grown on laminin or collagen, SMC on fibronectin elastomers no longer reacted with an increased apoptosis to cyclic stretch plus exogenous ET-1, irrespective of their origin, artery or vein.

The simultaneous $\mathrm{ET}_{\mathrm{B}} \mathrm{R}$-mediated growth response, on the other hand, was affected neither by fibronectin nor laminin both in the arterial and venous SMC. This again indicates that the vessel type-specific response of the SMC to pressure overload is not based on the terminal differentiation of these cells but presumably depends on the different composition of the extracellular matrix in these blood vessels.

This notion is supported by earlier studies showing that fibronectin can modulate the phenotype of vascular SMC through interaction with specific integrin receptors (outsidein signalling. ${ }^{18}$ ). Moreover, it has been suggested that the action of certain growth factors such as PDGF or angiotensin II depends on such cell-matrix interactions. ${ }^{19,20}$ Immunohistochemical analysis of fibronectin in cross sections of both the rabbit carotid artery and jugular vein, however, revealed a uniform distribution of this matrix protein in the media (not shown). Although principally capable of influencing vascular remodelling in response to deformation-induced activation of the endothelin system, fibronectin per se thus cannot be responsible for the differential phenotypic response of the native arterial and venous SMC.

\section{Conclusions}

The aforementioned findings demonstrate that pressure (i.e. deformation)-induced changes in expression of the endothelin system in the vessel wall are likely to play an important role in the adaptative but often exaggerated remodelling of both arteries and veins in response to a brief (angioplasty) or prolonged (bypass surgery, arterial hypertension) pressure overload. The observed differential phenotypic changes of native arterial and venous SMC (apoptosis versus proliferation) appear to be related to differences in the cell-matrix interaction rather than an arteriovenous predetermination of their phenotype.

\section{Materials and Methods}

\section{In situ model}

Segments of the common carotid artery and external jugular vein of male New Zealand white rabbits were prepared and perfused with Tyrode solution as described. ${ }^{8,9}$ In experiments with endothelin receptor antagonism, BQ123 or BQ788 (Alexis, Grünberg, Switzerland) were added to the luminal perfusate at a concentration of $1 \mu \mathrm{mol} /$ $L$ during the final 20 min of perfusion and throughout the subsequent incubation of the segments. Vessel segments were incubated at $37^{\circ} \mathrm{C}$ and $5 \% \mathrm{CO}_{2}$ in Waymouth medium (Life Technologies, Karlsruhe, Germany) containing $10 \%$ foetal bovine serum (FBS), $50 \mathrm{U} / \mathrm{mL}$ penicillin, $50 \mu \mathrm{g} / \mathrm{mL}$ streptomycin, $10 \mathrm{U} / \mathrm{mL}$ nystatin, $5 \mathrm{mmol} / \mathrm{L}$ HEPES (N-[2-Hydroxyethyl]piperazine- $\mathrm{N}^{\prime}$-[2-ethanesulphonic acid]) and $5 \mathrm{mmol} / \mathrm{L}$ TES (N-tris-[Hydroxymethyl]methyl-2-aminoethanesulphonic acid) for up to $36 \mathrm{~h}$.

\section{Superfusion bioassay}

Four ring segments (3-4 mm wide) were tested simultaneously by mounting them between force transducers and a rigid support for measurement of isometric force (TSE, Bad Homburg, Germany). They were superfused at $1 \mathrm{~mL} / \mathrm{min}$ with warmed $\left(37^{\circ} \mathrm{C}\right)$, oxygenated $\left(\mathrm{PO}_{2}>300 \mathrm{mmHg}\right)$ Krebs-Henseleit solution, $\mathrm{pH} 7.4$ with passive tension adjusted over a $30-\mathrm{min}$ equilibration period to $0.5 \mathrm{~g}$. Thereafter, increasing doses of endothelin-1 or the $E T_{B}-R$ antagonist 
sarafotoxin 6c (Alexis, Grünberg, Germany) were applied as bolus injections in $30 \mathrm{~min}$ intervals, and the ensuing constrictor response was monitored with the aid of a digital PC-operated analysis system (Biosys, TSE).

\section{Cell culture}

SMC from the aorta and vena cava of male Wistar rats $(200-250 \mathrm{~g}$ body weight) and from the rabbit carotid artery and jugular vein were isolated by the explant technique and cultured in Waymouth medium supplemented with $10 \%$ FBS, $50 \mathrm{U} / \mathrm{mL}$ penicillin, $50 \mu \mathrm{g} / \mathrm{mL}$ streptomycin, $10 \mathrm{U} / \mathrm{mL}$ nystatin, $5 \mathrm{mmol} / \mathrm{L}$ HEPES and $5 \mathrm{mmol} / \mathrm{L}$ TES, as previously described. ${ }^{11}$ Cells at passages 2 or 3 were seeded into BioFlex ${ }^{\circledR}$ collagen type I, laminin or fibronectin (Pronectin) 6-well plates (Flexcell Inc., Hillsborough, NC, USA) and used for the experiments from approximately $50 \%$ (proliferation studies) to $80 \%$ confluence (gene expression/apoptosis studies). SMC identity was confirmed after fixation with $p$-formaldehyde by positive immunostaining for smooth muscle $\alpha$-actin (antibodies from Sigma Aldrich, Deisenhofen, Germany).

For stretching of the cells, the conditioned medium was replaced by $2 \mathrm{~mL}$ of fresh medium, supplemented as described except for the omission of serum, $2 \mathrm{~h}$ before the start of the experiment. If any test compounds were to be administered, they were added $30 \mathrm{~min}$ before commencing of the stretch protocol. The 6-well plates were then mounted in a FlexerCell FX-3000 base plate (Flexcell) placed in an incubator and the SMC stretched for $6 \mathrm{~h}$ with $15 \%$ elongation at $0.5 \mathrm{~Hz}$. Elongation time was adjusted to $50 \%$ of total running time resulting in consecutive cycles of $1 \mathrm{~s}$ stretch and $1 \mathrm{~s}$ release.

\section{RT - PCR analysis}

Isolation of total RNA, CDNA synthesis and semi-quantitative PCR analysis of ppET-1, ECE-1, $E T_{A}-R$ and $E T_{B}-R$ mRNA expression with amplification of elongation factor-1 (EF-1) CDNA as an internal standard was performed as described. ${ }^{8,9} \mathrm{EF}-1$ expression was not pressure-sensitive as previously demonstrated..$^{8,9}$

\section{Immunohistochemistry}

Formaldehyde-fixed sections of the carotid artery and jugular vein were embedded in paraffin blocks of which $7 \mu \mathrm{m}$ thick sections were cut. After paraffin removal (boiling of the glass-fixed sections six times for $5 \mathrm{~min}$ in $10 \mathrm{mmol} / \mathrm{L}$ sodium citrate, $\mathrm{pH} \mathrm{6.0),} \mathrm{they} \mathrm{were} \mathrm{inactivated} \mathrm{in}$ $10 \mathrm{mmol} / \mathrm{L}$ Tris buffer, $\mathrm{pH} 7.6$ containing $3 \%(\mathrm{v} / \mathrm{v})$ hydrogen peroxide followed by blocking of non-specific binding sites for $20 \mathrm{~min}$ at room temperature with $10 \%(\mathrm{w} / \mathrm{v})$ bovine serum albumin in Hank's balanced salt solution (Life Technologies). The primary monoclonal anti-PCNA antibody (DAKO, Hamburg, Germany) was diluted $1: 100$ in $10 \mathrm{mmol} / \mathrm{L}$ Tris buffer, $\mathrm{pH} 7.6$ and incubated with the mounted sections for $2 \mathrm{~h}$ at room temperature. After thoroughly rinsing with $10 \mathrm{mmol} / \mathrm{L}$ Tris buffer, $\mathrm{pH} 7.6$, a peroxidase-coupled secondary antibody (anti-mouse, DAKO Envision ${ }^{\mathrm{TM}}$ ) was added and incubated with the sections for $30 \mathrm{~min}$ at room temperature. Thereafter, they were rinsed again, incubated for $30 \mathrm{~min}$ at room temperature with the AEC chromogen solution (DAKO), counter-stained with haematoxylin (Merck, Darmstadt, Germany), rinsed for 10 min with water, and finally mounted with Aquamount sealing medium (Gurr, Hanau, Germany). The stained sections were analyzed by light microscopy with dark brown nuclei counted as PCNA-positive, i.e. proliferating cells. In some experiments, an anti-Ki67 monoclonal antibody (MIB-1, DAKO) was used in essentially the same way as described, with qualitatively similar results as with the anti-PCNA antibody.

\section{Transmission electron microscopy (TEM)}

Preparation of sections for TEM analysis was performed essentially as described. ${ }^{21}$ Segments of the carotid artery or jugular vein were fixed with $1.5 \%(\mathrm{v} / \mathrm{v})$ glutaraldehyde and $1.5 \%(\mathrm{v} / \mathrm{v})$ formaldehyde in $150 \mathrm{mmol} / \mathrm{L}$ HEPES (pH 7.35, buffer osmolality $300 \mathrm{mosmol} / \mathrm{kg}$ ) for 1 day at $4{ }^{\circ} \mathrm{C}$. After this period, the segments were osmicated $(1 \%$

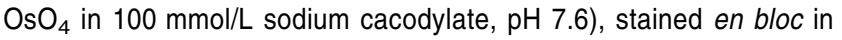
half-saturated aqueous uranyl acetate overnight, dehydrated with an ascending series of acetone $(70-100 \%)$ and then embedded in araldite $\left(60^{\circ} \mathrm{C}, 3\right.$ days). The resulting blocks were cut into $70 \mathrm{~nm}$ sections, which were counter-stained with lead citrate (Ultrostainer, Leica, Bensheim, Germany), and analyzed with an EM 900 transmission electron microscope (LEO, Oberkochen, Germany). Primary magnifications for analysis were 700-20 000-fold.

\section{Staining of nuclear DNA with Hoechst 33342 and immunofluorescence analysis}

After perfusion of the segments with Tyrode solution for $6 \mathrm{~h}$ they were incubated in medium for the times indicated. Thereafter, the segments were fixed with $5 \%(\mathrm{v} / \mathrm{v})$ formaldehyde in $145 \mathrm{mmol} / \mathrm{L}$ sodium chloride, $10 \mathrm{mmol} / \mathrm{L}$ HEPES for $12 \mathrm{~h}$ at $4^{\circ} \mathrm{C}$ followed by addition of the DNAbinding fluorescent dye Hoechst $33342(10 \mu \mathrm{g} / \mathrm{mL}$; Calbiochem, Bad Soden, Germany) for $72 \mathrm{~h}$. The fixed dye-treated segments were then embedded in paraffin. From these blocks $3 \mu \mathrm{m}$ thick cross sections were cut and examined by fluorescence microscopy at 400 -fold magnification. Only those nuclei were judged apoptotic that showed definite chromatin condensation or fragmentation. Cultured SMC were stained as described previously ${ }^{10}$ and analyzed in the same way as the cross sections of the segments.

Proliferation of cultured SMC was estimated by immunofluorescence analysis by using both the monoclonal anti-PCNA antibody and a monoclonal antibody against Ki67 (see above) and a secondary antimouse antibody labelled with Alexa 488 (Molecular Probes, via MoBiTec, Goettingen, Germany) according to standard procedures. The percentage of proliferating cells was calculated on the basis of total cell number relative to Ki67-positive nuclei counted from parallel images.

\section{Determination of caspase-3 activity}

After 2-36 $\mathrm{h}$ incubation in medium, the segments were snap-frozen in liquid nitrogen and pulverised with the aid of a mortar and pestle. The resulting fine powder was suspended in $100 \mu \mathrm{L}$ of extraction buffer $(50 \mathrm{mmol} / \mathrm{L}$ HEPES, $5 \mathrm{mmol} / \mathrm{L}$ EGTA, $50 \mathrm{mmol} / \mathrm{L} \mathrm{KCl}, 2 \mathrm{mmol} / \mathrm{L}$ $\mathrm{MgCl}_{2}, 1 \mathrm{mmol} / \mathrm{L}$ DTT, $167 \mu \mathrm{mol} / \mathrm{L}$ Pefablock, $1.5 \mu \mathrm{mol} / \mathrm{L}$ pepstatin A and $2 \mu \mathrm{mol} / \mathrm{L}$ leupeptin, $\mathrm{pH}$ 7.4) followed by three cycles of freeze thawing. The samples were centrifuged at $10000 \times g$ and the supernatant was diluted $1: 6$ in ICE buffer $(100 \mathrm{mmol} / \mathrm{L}$ HEPES, $10 \%(\mathrm{w} / \mathrm{v})$ sucrose, $0.1 \%(\mathrm{w} / \mathrm{v})$ Triton X-100, $10 \mathrm{mmol} / \mathrm{L}$ DTT and $0.1 \mathrm{mg} / \mathrm{mL}$ bovine serum albumin, $\mathrm{pH}$ 7.5). The protein content was measured with a modified Bradford protein assay (Biorad, Munich, Germany) according to the manufacturer's instructions. Protein concentrations were adjusted to approximately $1 \mathrm{mg} / \mathrm{mL}$, and $200 \mu \mathrm{L}$ of this extract were incubated for $30 \mathrm{~min}$ at $30^{\circ} \mathrm{C}$ with the caspase-3 specific substrate, DEVD-AFC (Asp-Glu-Val-Asp-7-amino-4-trifluoromethyl-coumarin), at a concentration of $20 \mu \mathrm{mol} / \mathrm{L}$. After the incubation, $150 \mu \mathrm{L}$ of each sample were transferred to a 96-well plate and the ensuing fluorescence monitored at an excitation wavelength of 405 and $510 \mathrm{~nm}$ emission in an fmax fluorescence reader (Molecular Devices, Munich, Germany). The fluorescence intensity of the AFC released was calculated as nmol of substrate released per $\mathrm{mg}$ of 
protein and minute by using standards of known concentration and the SOFTmax PRO- $f$ software (Molecular Devices).

\section{Statistical analysis}

Unless indicated otherwise, results are expressed as means \pm S.E.M. of $\mathrm{n}$ observations with cells or segments obtained from different animals. One sample $t$-test with two-sided $P$ value, student's unpaired $t$-test or one-way analysis of variance followed by Bonferoni multiple comparisons test or Dunnett post test were used as appropriate to determine the statistical significance of differences between the means and/or the means and control with $P<0.05$ considered significant.

\section{Acknowledgements}

This work was supported by the Deutsche Forschungsgemeinschaft (grant He 1587/7-3). The expert technical assistance of Annette Bennemann and Renate Dohrmann is gratefully acknowledged.

\section{References}

1. Dobrin PH (1983) Vascular mechanics. In: Handbook of Physiology. Section 2: The Cardiovascular System, Volume 3: Peripheral Circulation and Organ Blood Flow, Part I. Shepherd JT and Abboud FM eds. Bethesda: American Physiological Society, pp. 65-102

2. Hamet P, Moreau P, Dam TV, Orlov SN, Tea BS, de Blois D and Tremblay J (1996) The time window of apoptosis: a new component in the therapeutic strategy for cardiovascular remodeling. J. Hypertens. (Suppl. 14): S65 - S70

3. Yanagisawa M, Kurihara H, Kimura S, Tomobe Y, Kobayashi M, Mitsui Y, Yazaki Y, Goto K and Masaki T (1988) A novel potent vasoconstrictor peptide produced by vascular endothelial cells. Nature 332: 411-415

4. Janakidevi K, Fisher MA, Del Vecchio PJ, Tiruppathi C, Figge J and Malik AB (1992) Endothelin-1 stimulates DNA synthesis and proliferation of pulmonary artery smooth muscle cells. Am. J. Physiol. 263: 1295-1301

5. Yamazaki T, Komurol, Kudoh S, Zou Y, Shiojimal, Hiroi Y, Mizuno T, MaemuraK, Kurihara H, Aikawa R, Takano H and Yazaki Y (1996) Endothelin-1 is involved in mechanical stress-induced cardiomyocyte hypertrophy. J. Biol. Chem. 271: $3221-3228$

6. Wang X, Douglas SA, Louden C, Vickery-Clark LM, Feuerstein GZ, Ohlstein EH (1996) Expression of endothelin-1, endothelin-3, endothelin-converting enzyme-1, and endothelin-A and endothelin-B receptor mRNA after angioplasty-induced neointimal formation in the rat. Circ. Res. 78: 322-328
7. Rosendorff C (1997) Endothelin, vascular hypertrophy, and hypertension. Cardiovasc. Drugs Ther. 10: 795-802

8. Lauth M, Wagner AH, Cattaruzza M and Hecker M (2000) Transcriptional control of deformation-induced preproendothelin-1 gene expression in endothelial cells. J. Mol. Med. 78: 441-450

9. Lauth M, Berger MM, Cattaruzza M and Hecker M (2000) Pressure-induced upregulation of preproendothelin-1 and endothelin $\mathrm{B}$ receptor expression in rabbitjugular vein in situ: implications for vein graft failure? Arterioscler. Thromb. Vasc. Biol. 20: 96-103

10. Cattaruzza M, Dimigen C, Ehrenreich $\mathrm{H}$ and Hecker M (2000) Stretch-induced endothelin B receptor-mediator apoptosis in vascular smooth muscle cells. FASEB J. 14: $991-998$

11. Safar ME, Girerd X and Laurent S (1996) Structural changes of large conduit arteries in hypertension. J. Hypertens. 14: 545-555

12. Lemson MS, Tordoir JH, Daemen MJ and Kitslaar PJ (2000) Intimal hyperplasia in vascular grafts. Eur. J. Vasc. Endovasc. Surg. 19: 336-350

13. Yang Z, Krasnici N and Luscher TF (1999) Endothelin-1 potentiates human smooth muscle cell growth to PDGF: effects of ETA and ETB receptor blockade. Circulation 100: 5-8

14. Wagner AH, Krzesz R, Gao D, Schroeder C, Cattaruzza M and Hecker M (2000) Decoy oligodeoxynucleotide characterization of transcription factors controlling endothelin-B receptor expression in vascular smooth muscle cells. Mol. Pharmacol. 58: 1333-1340

15. Caro CG, Pedley TJ, Schroter RC and Seed WA (1978) The mechanics of the circulation. Oxford: Oxford University Press.

16. Diep QN, Intengan HD and Schiffrin EL (2000) Endothelin-1 attenuates omega3 fatty acid-induced apoptosis by inhibition of caspase-3. Hypertension 35: $287-$ 291

17. Shanahan CM, Weissberg PL (1998) Smooth muscle cell heterogeneity: patterns of gene expression in vascular smooth muscle cells in vitro and in vivo. Arterioscler. Thromb. Vasc. Biol. 18: 333-338

18. Wilson E, Sudhir K and Ives HE (1995) Mechanical strain of rat vascular smooth muscle cells is sensed by specific extracellular matrix/integrin interactions. J. Clin. Invest. 96: 2364-2372

19. Hu WY, Fukuda N, Satoh C, Jian T, Kubo A, Nakayama M, Kishioka $H$ and Kanmatsuse K (2000) Phenotypic modulation by fibronectin enhances the angiotensin II-generating system in cultured vascular smooth muscle cells. Arterioscler. Thromb. Vasc. Biol. 20: 1500-1505

20. Mawatari K, Liu B and Kent KC (2000) Activation of integrin receptors is required for growth factor-induced smooth muscle cell dysfunction. J. Vasc. Surg. 31: 375-381

21. Ochs M, Nenadic I, Fehrenbach A, Albes JM, Wahlers $\mathrm{T}$, Richter $\mathrm{J}$ and Fehrenbach H (1999) Ultrastructural alterations in intraalveolar surfactant subtypes after experimental ischemia and reperfusion. Am. J. Respir. Crit. Care Med. 160: 718-724 